\title{
Information Philosophy in China: Professor Wu Kun's 30 Years of Academic Thinking in Information Philosophy
}

\section{Guowu Li}

Xi'an Jiaotong University, Xi'an Shiyou University, China

\begin{abstract}
Professor Wu Kun from Xi'an Jiaotong University of China has been studying information philosophy for 30 years. Actually, he might be said to have founded information philosophy in China. He thinks conceiving of information is one of the most fundamental areas in philosophy. He has done original and pioneering research in information ontology, epistemology, social information theory, information production theory, information evolution theory, information value, and information thinking directions. He is the first scholar to develop a completely new view of theories, systems, and methods about information philosophy.
\end{abstract}

Keywords: Wu Kun, information philosophy, theories, systems

Since 1980, Professor Wu Kun has been researching information philosophy and has been well known as "a pioneer or the first one in information philosophy".

The main academic contributions of Professor Wu Kun are his idea that the information concept deserves attention as one of the most fundamental areas in philosophy and his laying the foundations of information philosophy. He has done pioneering and original research in information ontology, epistemology, social information theory, information production theory, information evolution theory, information value, and information thinking directions; therefore, he is the first scholar to set up a completely new view of theories, systems, and methods about information philosophy. He has published 13 monographs, such as Introduction to Information Theory (1987), A New Spirit of the Times - Philosophy Information (1989), Natural logic (1990), Evolution of Information World (1994), Information and Social Development (1998), Knowledge and Information's Economy (2000), Research on Philosophy Value (2002), Information Epistemology (2002a), Analogies and Criticism in Philosophy (2002), Theory • System • Method in Information Philosophy (2005), Information and Multi-Dimensional Interaction Mode Exploring in Western Development (2006), Information Philosophical Argument (2008a), Information, Systems and Complexity Thinking on Ancient Philosophy--Greece - China - India (2010); and 200 academic papers related to information philosophy. Professor Wu Kun's main symbols of academic achievement are the thesis named Information Philosophy Theory Chamber (1985) and monographs entitled Philosophy Information Introduction (1978) and Theory • system • method in information Philosophy (2005).

To better understand information philosophy and his contribution in this field, I will now summarize Professor Wu Kun's 30 years of academic history as below.

\section{Foundation of Information Philosophy (1980-1987)}

Since the middle of the 20th century, with the worldwide development and progress in the information technology revolution, information economy, information society, social information, and information philosophy have emerged.

In the early 1980s, with the introduction of related subjects, Chinese academia warmly discussed information problems, so information philosophy's founding was timely. In China, Professor Wu Kun is one of the few scholars who studies information problems. In 1980, Professor Wu Kun began to scientifically explain the relationship between matter and spirit. According to traditional philosophy, matter and spirit constitute the existence of two basic areas of the world, which are two opposing units. But are these two opposites reasonable? The material translated into spirit and 
spirit affecting the material, they both need an intermediate link to transform, transit, and contact each other. Professor Wu Kun thinks the one who can find out and explain the intermediate link scientifically will bring about an overall change of philosophy. Guided by this thought, Professor Wu Kun started his research. Later, he found out that "information" can be regarded as that basic conception introduced into philosophy and that acts as the interactive link between matter and spirit.

In July of 1980, Professor Wu Kun finished his first research paper named "Thinking - an advanced form of material and information activities" (Wu Kun, 1981a). In this paper, for the first time he considered information as a "material existence form and status manifestation". Then he proposed and also proved that information had three basic forms - in itself, for itself, and regeneration. Thirdly, he also raised the information field, imaging information, symbol information, and other information forms. Finally, he described the transition from the material to a spiritual process as an information activity process. It were these points in this paper that introduced information into philosophy and then laid the foundation for the basic premises of information ontology and epistemology.

In spring 1981, Professor Wu Kun completed his second paper named "Information Status and Role in Philosophy" (Wu Kun,1981b). Information was defined as its own manifestation of material existence and status. (This definition is the last half-sentence of the standard definition of "information"). And, more accurately, he identified three basic configurations of information. In addition, he also proposed a qualitative theory of three different properties; last, he pointed out the status and role of information in ontology and epistemology.

In autumn 1981, Professor Wu Kun finished his third research paper with the title "Measurement of Information Philosophy" (Wu Kun, 1981c). In this paper, he differentiated relative information from absolute information and gave mathematical models of relative information and dynamic relative information, which differ from Shannon's.

In April 1982, Professor Wu Kun completed the first draft of Introduction to Information Theory as his bachelor's thesis. Chapter 1, entitled "Investigation on Information Intermediary," was published in Lanzhou Science 5, 1984. "Information Philosophy Theory Chamber", published in Humanities Magazine 1, 1985, represents this book's basic points. Very soon, Introduction to Information Theory was published by Shaanxi People's Publishing House. The completion of this book and its related achievement marked the official creation of information philosophy in China. According to the completion of Introduction to Information Theory and his bachelor's thesis, we can say the creation of information philosophy dates back to 1982. But considering the book's publishing time, information philosophy took shape from 1985 to 1987.

For the first time, systematically and comprehensively, Professor Wu Kun framed many new conceptions, such as a qualitative theory of three different properties, absolute and relative amount of information, the relationship between information and some directions of philosophy, the conceptual level of ontology, information intermediary, information theory, differences and similarities in the philosophy of force and the philosophy of information, and other issues. All of these pioneering studies construct a kind of information theory that is different from practical information theory. It formally announced a new era of philosophy - information philosophy founded in China.

\section{Improvement of Information Philosophy (1985-2005)}

Information philosophy includes information ontology, epistemology, social information theory, information production theory, information evolution theory, information value, information thinking, and other contents. During the following 20 years, Professor Wu Kun has done much more research in these areas and set up his completely new view of theories, systems, and methods in this field. Now I would like to provide a brief introduction to it. 


\subsection{Putting Forward the Material and Information Dual Existence Theory - Founding Infor- mation Ontology}

In the year of 1985, while Professor Wu Kun was giving the lecture on "Introduction to Dialectics of Nature" curriculum, he began to think about the issue of information ontology. In March 1987, he finished writing a new monograph, Natural Logic, which was published by Northwest University Press. In this book, he not only put forward the ontology methods "discarding the human being's understanding intermediaries" and "expressing nature by nature's name," but also described the whole of nature as a material and information dual existence, a dual evolution world whose contents, processes, and mechanisms were furthermore defined, explained, and discussed in detail. All these achievements marked the perfection and maturity of basic concepts and theories of ontology proposed by Professor Wu Kun.

\subsection{Putting Forward the Material and Information Dual Evolution Theory - Founding Informa- tion Evolutionism}

In April of 1988, Professor Wu Kun started to write Evolution of Information World, finished it in 1993, then had it published in 1994 by Northwest University Press. This book perfected his material and information dual evolution theory.

\subsection{Putting Forward Information Intermediary Theory - Founding Information Epistemology}

Professor Wu Kun called his information epistemology "information intermediary of epistemology". It consists of two parts. One is "information intermediary hypothesis," and the other is "cognitive process and mechanism's construction and the virtual hypothesis." The epistemology part of Introduction to Information Theory only involves the first aspect of this doctrine. In his later study, he finished and published "Cognitive, Relative Moving Information Constructive Activity in Multi-level Intermediate" (Wu Kun, 1989a), "The Cognitive Style of Human Being" (Wu Kun, 1989b), "Levels of the Main Information Activities and its Interaction" Wu Kun, 1993), Identification by Differences, Construction by Intermediaries, Virtual by constructing - General Processes and Mechanisms of Information Cognitive (Wu Kun, 2004). In 2002, Information Epistemology (Wu Kun, 2002a) was finished. The publication of these papers and monographs marked the perfection of his epistemological theory.

\subsection{Putting Forward the Idea that Information Production Is the Essence of Human Produc- tion - Founding Production Information}

In 1994, Professor Wu Kun began to pay more attention to the information economy, information society field research. In this field, he has published nearly 20 papers and two monographs, Information and Social Development (Wu Kun, 1998), Knowledge and Information Economy (Wu Kun, 2000a). Professor Wu Kun considers information science, information technology, information economy, information society, information socialization, and social information theory and practice as a uniform wave era during the last few years of the 20th century, and his endeavours marked a comprehensive study of information philosophy. At last, he put forward new ideas and theories of information science, information production, and productivity directions. In Professor Wu Kun's view, the material can be conserved, it is immortal, and it can only be changed in form, but cannot be created or destroyed. However, information cannot be conserved, and information reconstruction and creation can lead to material existence that resists changing. Therefore, human production can only be information production, and productivity can only be human information productivity. These results marked the establishment and improvement of social information and information production theory system. 


\subsection{Systematically Carding Humanity's Scientific Paradigm Change and Development - Founding Information Thinking Theory}

In 1998, Professor Wu Kun came to study the theory of information thinking. He explored scientific ways of thinking in human beings and clearly defined "physical thinking," "energy thinking," and "information thinking." In May 2000, Professor Wu Kun completed a 30,000-word paper titled "Material thinking • Energy thinking • Information Thinking," which was published in The Academic (Wu Kun, 2002b). After that, Professor Wu Kun studied the relationship between complexity and information thinking, the relationship between the third technological revolution and information systems and integrated them with the complex picture of the world. On this basis, he put forward his own standards and theories about revolution in science and the technological revolution. Later, he published "Revolution on Complexity and Scientific Way of Thinking" (Wu Kun, 2002c), "Information Thinking - a New Scientific Way of Thinking in Information Age" (Wu Kun, 2003a). These results marked the foundation of Professor Wu Kun's theory about information thinking.

\subsection{From Dual Dimension of Both Material Value and Information Value - He Proposed the Value of Heaven and Founded the Value of Information}

In 1997, Professor Wu Kun published his first paper about the value of information, entitled "Outline of the Philosophy Value - Explained Philosophy Value with the Name of Natural Body" (Wu Kun, 1997). Later, he published "Heaven Value and Human Value" (Wu Kun, 1999a), "Several Problems Related to the Philosophy Value" (Wu Kun ,1999b), "Value Fact, Value Reflect, and Value assessment" (Wu Kun, 2000b), "Value Conflicts in the Network Culture" (Wu Kun, 2001), and other papers. In 2002, Value Philosophy Problems was published by China Social Sciences Press. Professor Wu Kun is the lead author and chief editor of this book. In all of this research, Professor Wu Kun defined "value is things (including material, information and spirit, the main form of information) through the internal and external interaction realized by effect." He also conducted more research on value philosophy problems. Based on the information economy, information society, and information network, all of which lead to the corresponding evolution of economic, political, and cultural ideas, and other aspects of life, he further explored the social value of information. These results marked the foundation of his information value theory.

\subsection{Creation of a Grand, Systematic Theoretical System of Information Philosophy}

In October 2001, Professor Wu Kun began to collect his years of research work as his own independent National Social Science Fund. In June 2002, the National Social Science Fund was granted, Professor Wu Kun quickened his steps of establishing his complete theoretical system in information philosophy. In June 2003, he produced a monograph with more than 700,000 words, 10 Codes, and 40 Chapters, Information Philosophy - Theory, System and Method, marking the ending of the National Social Science Fund Project. In March 2005, the Commercial Press published this book.

Five famous Chinese experts, Wang Yutian, He Zuorong, Pang Yuanzheng, Shen Zhongying, and Meng Xianjun gave Professor Wu Kun's work a "level A". Based on the summarized results of the latest achievements of information science, they concluded that Professor Wu Kun has built an all-around, mutli-angle theoretical system of information philosophy, explored the philosophical problems, and created a complete set of philosophical theories to understand, interpret, and change the world through the information dimension. "The result is an original, pioneering, academic masterpiece with its own style. The work with its novel academic view, full content, close logic, concise description, has reached a pretty high level. The result, not only with its original argument, link of before and after, but also its breadth, a high degree of structure, has indeed become the style of his own. The outcome is the first systematical work in information philosophy, making much preparation for the foundation of the development of its discipline, and having important theoretical value" (Wu Kun,2005). One book review stated, "As the results comprehensively building philosophy in the element of information philosophy (first philosophy) level, It is a specific 
form of modern philosophy, so the results have an extremely high academic value of theoretical innovation in terms of development of Marxist philosophy, or critique and transformation of traditional philosophy, or new construction of a new era of philosophy" (Zhang Yu, 2005).

\section{The Latest Information Philosophy (2005 - present)}

After 2005, Professor Wu Kun started to evaluate and sort out different schools of the concepts of ancient and modern philosophy with his own method, continued to deepen his philosophical studies, and expanded the corresponding comparative study, which included sorting out and evaluating relevant ancient philosophical thinking, conducting comparative studies between information philosophy and Marxist philosophy, systematical philosophy and information philosophy, and information philosophy and contemporary Western philosophy. In recent years, Professor Wu Kun has published a series of papers in this direction, as well as two monographs, Argument in Information Philosophy (Wu Kun, 2008) and Information, Systems and Complexity Thinking of Ancient Philosophy - Greece • China • India (Wu Kun, 2010). In September 2009, the Third Frontier Forum on Social Science - Contemporary Construction of Chinese Academic System conference was held in Xi'an, China, jointly sponsored by China Social Science magazine, Shaanxi Province Social Science Association, and Northwest University. Professor Wu Kun presented a paper entitled "Basic Problems of Philosophy and Philosophy Fundamental Shift" and made a speech at the conference. In the executive summary of this paper, Professor Wu Kun mentioned that, due to the uncertainty of "existence," the basic question of philosophy needs to be truly understood and grasped. Specific expression lies in the detailed division of "existence." The evidence of the "relationship between the material and spirit" about the basic question of philosophy lies in the "existence" of two major areas, the material and spirit. Historically, it was a basic mode through which traditional philosophy divides "existence" and determines basic areas and the general nature of traditional philosophy. The fundamental steering of philosophy is the changing expression of basic philosophical questions, and its basis lies in the division mode. So far, although the development of human philosophy in certain fields of study has achieved conversion between research priorities and problems of concern, its foundation of existence theory and epistemology has never undergone any fundamental changes. This is the fundamental commitment and concrete interpretation of binary oppositions of matter and spirit, subject and object. Therefore, human philosophical development has never had any fundamental and theoretical conversion. Because Professor Wu Kun has introduced the information concept as one of the most basic concepts in philosophy, he totally changed the specific way to express basic philosophical questions. Information philosophy has achieved the first fundamental shift for human philosophy, and thus led to a fundamental change in human philosophy.

Finally, I want to emphasize that Professor Wu Kun is of high academic style and academic rank. He has studied in the field of information philosophy for 30 years. Although interferences occurred, they have never stopped Professor Kun Wu's research. It is, indeed, a tiring, but rewarding career. In 30 years' thinking, Professor Wu Kun's basic ideas and theories about information philosophy haven't changed. His academic thinking and mind path have stayed consistent and uniform. From them, we can infer the kind of careful, honest, and serious working attitude Professor Wu Kun has. This is an invaluable quality especially when Chinese academia is so impetuous.

\section{References}

Wu Kun. (1981a). Thinking: An advanced form of material and information activities. Series Journal of Lanzhou University student paper, 1, 1-10.

Wu Kun. (1981b). Information status and role in philosophy. Potential Science Journal, 3, 53-60.

Wu Kun. (1981c). Measurement of information philosophy. Paper presented in Lanzhou University's scientific paper's report annual meeting, 1981.

Wu Kun. (1984). Investigation on information intermediary. Lanzhou Science, 5, 15-23.

Wu Kun. (1985). Information philosophy theory chamber. Humanities Magazine, 1, 30-36.

Wu Kun. (1987). Introduction to information theory. Xi'an: Shaanxi People's Publishing House. 
Wu Kun. (1989a). Cognitive, relative moving information constructive activity in multi-level intermediate. Changsha teachers' college science, 3, 20-26.

Wu Kun. (1989b). The cognitive style of human being. Seeking Science, 3.

Wu Kun. (1990). Natural logic. Xian: Northwest University Press.

Wu Kun. (1993). Levels of the main Information activities and its interaction. Northwest University Science, 3.

Wu Kun. (1997). Outline of the philosophy value: Explained philosophy value with the name of natural body. Humanities Magazine, 2, 18-21.

Wu Kun. (1998). Information and social development. Chengdu: Southwest Financial University Press.

Wu Kun. (1999a). Heaven value and human value. In Value and development. Shaanxi: Shaanxi People's Education Press.

Wu Kun. (1999b). Several problems related to the philosophy value. Journal of Social Science Series, 5.

Wu Kun. (2000a). Knowledge and information economy. Xian: Northwest University Press.

Wu Kun. (2000b). Value fact, value reflect, and value assessment. The academic, 5.

Wu Kun. (2001). Value conflicts in the network culture. Shenzhen University, 5.

Wu Kun. (2002a). Information epistemology. Beijing: China Social Sciences Press.

Wu Kun. (2002b). Material thinking: Energy thinking: Information Thinking. The academic, 2.

Wu Kun. (2002c). Value philosophy problems. Beijing: China Social Sciences Press.

Wu Kun. (2002c). Revolution on complexity and scientific way of thinking. Dialectics of Nature, 10.

Wu Kun. (2003a). Information thinking: A new scientific way of thinking in information age. Xi'an Jiaotong University Technology, 3.

Wu Kun. (2003b). Information philosophy: Theory, system and method. Beijing: Commercial Press.

Wu Kun. (2004). Identification by differences, construction by intermediaries, virtual by constructing: general processes and mechanisms of information cognitive. In Science: Cognitive: Awareness. Jiangxi: Jiangxi People's Publishing House.

Wu Kun. (2005). Information philosophy: Theory, system, method. Beijing: Commercial Press

Wu Kun. (2008a). Information philosophical argument. Xian: Jiaotong University Press.

Wu Kun. (2008b). Argument in information philosophy. Shanghai: Jiaotong University Press.

Wu Kun. (2009). Basic problems of philosophy and philosophy fundamental shift. Paper presented at Third Frontier Forum on Social Science: Contemporary Construction of Chinese Academic System conference, Xian, September 2009.

Wu Kun. (2010). Information, systems and complexity: Thinking of ancient philosophy: Greece, China, India. Beijing: Commercial Press.

Zhang Yu. (2005).All-round display of information philosophy: Review of "Information philosophy: Theory, system and method". Technology Daily, July 6, 2005

\section{About the Author}

Guowu Li

Born in 1972 in Xi'an,China. Ph.D., Xi 'an Jiaotong University, Institute of Humanities and Social Sciences. Northwestern University, Master of Economics, Associate Professor, University of Petroleum in Xian. Research direction: information philosophy. Winner of the People's Government of Shaanxi Province Higher Education teaching achievement prize in 2001; and, in recent years, of first prizes in "Information, Intelligence and Logic", "Xi 'an Jiaotong University Journal", "News Knowledge", "Journal of Northwestern University". Over 20 articles in information philosophy. 